\title{
A systematic review of the accessibility, acceptability, safety, efficiency, clinical effectiveness and cost-effectiveness of private providers of elective surgical services compared with public providers
}

\author{
Ilke Akpinar ( $\square$ iakpinar@ihe.ca ) \\ Institute of Health Economics \\ Erin Kirwin \\ Institute of Health Economics \\ Lisa Tjosvold \\ Institute of Health Economics \\ Dagmara Chojecki \\ Institute of Health Economics \\ Jeff Round \\ Institute of Health Economics
}

\section{Research Article}

Keywords: Private surgical facilities, Independent sector treatment centres, Systematic review

Posted Date: November 2nd, 2021

DOI: https://doi.org/10.21203/rs.3.rs-958399/v1

License: (9) (1) This work is licensed under a Creative Commons Attribution 4.0 International License. Read Full License 


\section{Abstract}

Many publicly funded health systems use a mix of privately and publicly operated providers of care to deliver elective surgical services. We review the role of private elective surgical provision within publicly funded health systems in high-income countries. The outcomes evaluated include accessibility, acceptability, safety, clinical effectiveness, efficiency, and cost/cost-effectiveness. Twenty-seven articles met the review inclusion criteria. We found mixed results across each of our reported outcomes. Wait times were shorter for patients treated in private facilities in most studies, and inequalities by age and socioeconomic deprivation were found to increase with private provision in some studies. Acceptability results were mixed, with most studies finding no differences between public and private provision and others finding higher satisfaction at public facilities. The results for safety outcomes were divided, but most studies that found improved safety outcomes in private facilities, noting that private patients had a lower preoperative risk of complications. Clinical effectiveness was similar in most studies, with differences in outcomes mainly attributed to patient selection or prosthesis choice. Very few studies reported cost and cost-effectiveness outcomes, and just two included studies concluded that private facilities are economically viable.

\section{Background}

There is widespread interest in improving access and reducing wait times for publicly funded health services while simultaneously reducing health care costs. These improvements have been significant in the context of elective surgeries. Quality improvement interventions which redesign access to services, make changes to market structures, and create a competitive environment are advocated for in many countries, including Canada, the United Kingdom (UK), and Australia ${ }^{1}$. Although the use of private providers within the publicly funded health system has always been controversial, delivery side marketoriented reforms in health care have been adopted widely. Under typical reforms, universality of coverage through taxation remains, but a competitive environment has been introduced on the supply side.

With increasing pressures on public health systems internationally, there is a need to develop the evidence base on the effects of private elective surgical provision within public health systems. Many studies have been produced to investigate the various effects of private elective surgical provision, and systematic reviews and overviews have provided evidence on public health outcomes compared to private provision of health services. To our knowledge, no systematic reviews focus on the role of private provision of elective surgeries in publicly funded health systems.

This systematic review aims to identify the impact of introducing private sector surgical service provision within publicly funded health systems.

\section{Materials And Methods}

\subsection{Data sources and search strategy}

The literature search was designed to identify studies that investigated the accessibility, acceptability, safety, clinical effectiveness, efficiency, and costeffectiveness of private surgical facilities.

Relevant bibliographic databases (Ovid MEDLINE, OVID Embase, EBSCO EconLit) and grey literature sources (Google Advanced, The King's Fund, OECD, European Observatory, Commonwealth Fund, Conference Board of Canada, Fraser Institute) were searched by an information specialist (DC) between 14 and 21 May 2019. A search update was performed by a second information specialist (LT) between 26 March and 06 April 2021 on the same sources. Relevant studies published from January 2000 onwards were identified using a combination of controlled vocabulary (MeSH and EMTREE terms) and keywords relating to private non-hospital surgical facilities and the contracting out of services to them by the public health sector. Results of a scoping exercise suggested that the most widely targeted elective procedures for private provision were cataract and orthopedic surgery and so results were limited to articles on these procedures, and to English language publications. The goal was to capture any information on this topic (including empirical studies and broader reviews), so the search parameters were not limited to a particular study design.

Full details of the search strategy can be found in the Additional file 1.

\subsection{Inclusion and exclusion criteria}

Studies were included if they met the following criteria:

- Study design: Primary studies and systematic reviews

- Population: Adult patients who had a cataract or orthopedic surgery

- Intervention: Non-hospital/ hospital private surgical facilities

- Comparator: Surgical facilities operated by public sector health providers (e.g., National or regional health authorities)

- Outcome measures: Accessibility (waiting times, availability of health professionals or centres), acceptability (public/patient perceptions), safety/quality of care (readmission and complication rates), clinical effectiveness (need for revision), efficiency and cost/cost-effectiveness of private/ public surgical facilities

- Setting: Publicly funded health systems

Studies that did not report data on any of the pre-defined outcomes were excluded.

\subsection{Study selection}


Titles/abstracts identified from the main literature search were screened by two reviewers (IA and EK). Subsequently, full-texts of the potentially relevant articles were retrieved to ascertain whether they met all the eligibility criteria by the same researchers. Disagreements over eligibility were resolved by discussion. A third (JR) reviewer helped resolve uncertainty when needed.

We included any studies that evaluated the impact of private surgical facilities within publicly funded health systems and included at least one of the outcomes described above. We selected studies from Canadian provinces/territories and developed countries with a similar health system, including the UK, Australia, and some other European countries (Austria, Denmark, Italy, Netherlands, Norway). The focus of our evaluation was the provision of cataract and orthopedic services only.

\subsection{Data extraction}

This literature review aimed to summarize previous studies presenting evidence on the impact on accessibility, acceptability, safety, clinical effectiveness, efficiency, and cost/cost-effectiveness of treatments following the introduction of a private sector provision of surgical services primarily publicly operated health systems. Two reviewers (IA, EK) extracted data in duplicate from the selected primary studies. For studies with multiple publications, the most recent or most comprehensive publication was included as a key study, with supplemental information from other publications if necessary. Relevant systematic reviews were not included for analysis if they did not adequately address our scope on cataract and orthopedic surgery.

\section{Results}

\subsection{Description of selected studies}

Using the PRISMA (Preferred Reporting Items for Systematic Reviews and Meta-Analyses) diagram format, Figure 1 indicates the total number of candidate articles through the identification and selection process. The initial and updated main literature search identified 1378 citations (581 citations from MEDLINE, and 797 from EMBASE and EconLit electronic databases). 319 grey literature results were identified through the initial and updated Google internet searches.

After duplicates were removed, 1204 unique studies appeared relevant. The list of titles and abstracts was reviewed, and 57 studies were selected for fulltext review to assess if they provided information about impacts on accessibility, acceptability, safety, efficiency, clinical and cost-effectiveness of treatments following the introduction of private sector provision of surgical services (cataract, orthopedic procedures) within publicly funded health systems. Twenty-seven articles met the inclusion criteria to be analyzed for a critical narrative summary report ${ }^{2-28}$. The data extracted from each study is reported in table 1 and additional file 2, and described in detail in the following section.

Figure 1: PRISMA Flow Diagram of Study Selection

Table 1: Data extracted during the review

\subsection{Findings on private elective surgical provision within public health systems}

\subsubsection{Accessibility}

Access to health care is defined as the extent to which financial, organizational, geographical, and cultural barriers are minimized for patients ${ }^{29}$. Eleven papers from the UK, Australia, Denmark, Canada, Netherlands and Italy discussed the accessibility of services for cataract, hip, and knee patients and compared the private and public provision of these surgical procedures ${ }^{3,6,9,10,12,13,21,25-28}$. Among these studies, only two ${ }^{12,13}$ looked at accessibility related to patient preoperative/ general health status or symptom severity, and neither reached a definite conclusion about the relevance of these factors.

United Kingdom

Reforms in the UK introduced in 2006 allowed Independent Sector Treatment Centres (ISTCs) to operate within the UK health system. From 2006 onward, private hospitals were also allowed to enter the existing elective surgical treatment system and compete with the ISTCs and public hospitals ${ }^{25}$ for publicly funded treatments. Kelly and Stoye ${ }^{21}$ examined private providers' access to the market for elective hip replacement in the UK between April 2002 and March 2011. They found that waiting times did not depend on the nearest ISTC; however, the introduction of the private sector providers reduced waiting times at National Health Service (NHS) hospitals without any effect on surgical volumes. In a second paper, Kelly and Stoye ${ }^{25}$ evaluated different aspects of the impacts of private hospitals' entry on the publicly funded elective hip replacement surgery market. The authors found a $12 \%$ annual expansion in the size of the publicly funded elective hip surgeries and a decrease in wait times in public hospitals from 239 days (2002-03) to 92 (2012-13) days. In 201213 , median wait times were significantly lower at private hospitals than in public hospitals at 63 days and 92 days, respectively.

Kirkwood and Pollock ${ }^{9}$ conducted an ecological study of 154,766 patients receiving publicly funded primary hip arthroplasty (105,872 elective and 48,894 emergency cases) in Scotland between April 1993 and March 2013. They evaluated how the policy of commercial contracting to tackle waiting times impacted direct NHS provision and treatment inequalities. Inequalities by age and socioeconomic deprivation were found to increase with a private provision especially for the patients aged 85 years and over and those living in more socioeconomically deprived areas. Thus, they warned about the negative consequences of private sector provision on equitable access to care. 
Fitzpatrick et al. ${ }^{6}$ surveyed five English regions for 12 months and explored sociodemographic and health status factors associated with waiting times. Study results showed that publicly funded patients were 5.28 (95\% Confidence Interval [Cl] 4.22-6.59) more likely to report a wait time greater than three months for an outpatient appointment and 12.80 (95\% $\mathrm{Cl} 9.81-16.68)$ times more likely to report a wait time longer than six months for total hip replacement (THR) than the privately funded ones.

Australia

Pager and McCluskey ${ }^{12}$ compared day-case cataract surgery patients' priorities and satisfaction levels in Australia, surveying 42 public and 39 private patients. Results showed that mean surgery wait times for patients at public hospitals were nine times longer ( 38.2 vs 4.4 weeks, $p<0.001)$ than the private centre patients.

Canada

Koehoorn et al. ${ }^{10}$ assessed the effect of expedited surgical fees paid to physicians in reducing wait time and patient return to work time in public and private facilities in British Columbia. The study cohort consists of workers who accepted workers' compensation claims for meniscal injury and underwent knee surgery between 2001 and 2005. Study results showed that the median wait time for surgery was 22 and 24 days for expedited operations (public hospital and private clinic, respectively), compared to 37 days for non-expedited surgeries (public hospital only), a difference of almost two weeks.

Denmark

Two studies from Denmark investigated access for cataract and hip operations. The first study by Solborg Bjerrum et al. ${ }^{13}$ researched the epidemiology and mortality of patients who had cataract surgery in public hospitals and private facilities between 2004 and 2012 . Using data from 243,856 patient registries (411,140 cataract operations), the researchers showed that private facilities offer second eye surgery sooner than public facilities. The median time interval was seven days shorter for cataract surgery patients in private clinics, and with a statistically significant difference between groups ( $95 \% \mathrm{Cl}$ $[6.65,7.35] ; p<0.001)$.

A second study by Andersen and Jakobsen ${ }^{3}$ compared private and public hip clinics using a Danish Registry from 2007 to 2008 . The researchers evaluated the wait times from 36 public and 20 private hip replacement clinics and found that private clinics reduce wait times more than public clinics.

Netherlands

To evaluate differences in cataract surgery cost, quality of care, and efficiency, Kruse et al. ${ }^{26}$ conducted a comparative multilevel analysis using $2013-15$ reimbursement claim data and quality indicators. They found that ISTCs cataract surgery volume is slightly higher than the general hospitals, with an average of 0.91 and 0.84 cataract operations per care pathway, respectively.

In a cross-sectional study from the Netherlands, Tulp et al. ${ }^{28}$ examined the differences in healthcare quality and cost for five elective surgeries between the ISTCs and general hospitals, using 2017 data. Their analysis showed that cataract (1855.22 \pm 965.50 vs $1180.81 \pm 640.65)$, hip (379.51 \pm 184.63 vs 127.92 \pm 130.68 ), and knee surgeries (315.00 \pm 149.90 vs $163.07 \pm 182.84)$ were performed more frequently in public hospitals.

Italy

Moscone et al. ${ }^{27}$ compared healthcare quality between public and private hospitals treating publicly funded patients who received elective (hip or knee replacement) or emergency care (hip fracture) in the Lombardy region, Italy. Study results showed that even though there were more public than private hospitals (64 vs 46), private hospitals treat more hip and knee replacement patients. Ordinary least square (OLS) regression analysis results indicated that hip and knee surgery wait times are shorter in private hospitals by about 25 to $35 \%$. Comparing the OLS with an instrumental variable (IV) approach, the authors showed that unobserved factors such as patient morbidity were also important. OLS indicated lower wait times in private facilities, but this result was not significant using the IV approach.

\subsubsection{Acceptability}

Although the included studies offer little information on defining or assessing acceptability, a theoretical framework defines the concept as a patient's cognitive and emotional responses to the intervention ${ }^{30}$. From a health care perspective, the primary acceptability indicator is satisfaction level, and the included studies provide information on retrospective acceptability using satisfaction levels. In seven papers, two from the UK ${ }^{17,23}$, three from Australia ${ }^{2}$ 11,12 , one from Denmark ${ }^{3}$ and one from the Netherlands ${ }^{26}$, the acceptability of surgical services was discussed.

United Kingdom

Browne et al. ${ }^{23}$ conducted a prospective cohort study of 769 patients treated in six ISTCs and 20 NHS providers to compare the case-mix and patient reported outcomes of surgery. They assessed the change in patient-reported health status and health-related quality of life after three months for cataract surgery patients and after six months for hip and knee patients. In this study, roughly equivalent proportions of patients treated at ISTCs and NHS facilities (cataract surgery $97 \%$ versus $91 \%$; hip replacement $98 \%$ versus $92 \%$; and knee replacement $85 \%$ versus $87 \%$, respectively) described their operation results as excellent, very good, or good, irrespective of where they were treated.

Page 4/14 
Using survey data, Perotin et al. ${ }^{17}$ studied the effects of hospital ownership on the quality of information, care, privacy, dignity, hospitality, and procedural delays. Results showed that public sector hospitals provided better information and more choice, while private sector facilities offered a more comfortable, friendly, and clean environment. The authors stated that the results varied across patient groups and explained that differences in the quality of information between these two sectors were due to patient selection and other unobserved hospital characteristics, and not due to hospital ownership ${ }^{17}$.

\section{Australia}

Australian survey results for patients who received cataract care within the private and public sectors show that $90 \%$ of private sector patients were satisfied with the information they received, whereas $45 \%$ of public sector patients wanted more information. Public sector patients were less satisfied overall than private sector patients, although the level of satisfaction between groups was similar ${ }^{12}$.

Assessing satisfaction rates, Adie et al. ${ }^{2}$ conducted a prospective observational study on 331 hip and knee replacement patients in two public and two private high-volume joint replacement centres in Australia. They found almost $90 \%$ satisfaction rates in public and private patients at six and 12 months after surgery. After adjusting for the effect of patient expectation (expectations met in $76 \%$ of private centres and $64 \%$ of public centres at 12 months), private patients were less likely to be satisfied due to their higher expectations (adjusted odds ratio [aOR] for satisfaction at 12 months: 0.16 private vs public).

Naylor et al. ${ }^{11}$ surveyed satisfaction in Australian patients who underwent arthroplasty in eight public and seven private high-volume arthroplasty centres. The odds ratio (OR) for satisfaction was higher in public (1.78) but not statistically significant $(p=0.26)$. Private sector did better in hospitality (46.7\% vs $35.6 \%)$ and frequency of surgeon visitation $(76.4 \%$ vs $65.8 \%)$.

Denmark

A Danish study used survey results from 36 public and 20 private hip replacement clinics, Andersen and Jakobsen ${ }^{3}$ reported higher patient satisfaction with private clinics.

Netherlands

Using patient-reported data from a questionnaire given to Dutch cataract surgery patients from $2013-14$, Kruse et al. ${ }^{26}$ compared patient satisfaction between ISTCs and public hospitals. They used the Net Promoter Score to measure patient satisfaction and identified significantly higher scores among ISTC patients compared with public hospital patients.

\subsubsection{Safety}

Factors impacting patient safety in the outpatient surgery population include surgical preparedness, patient education, and clinically appropriate and accurate surgical procedures ${ }^{31}$. Several papers addressed safety considerations for elective surgical procedures: four from the UK ${ }^{5,23-25}$, two from Australia ${ }^{11,19}$, three from Denmark ${ }^{3,13,14}$, one from Norway ${ }^{18}$, and one from Italy 27.

United Kingdom

Browne et al. ${ }^{23}$ compared patient-reported outcomes of cataract surgery in six ISTC and 20 NHS providers from 2006 to 2007 . They found that patients treated in ISTCs were less likely to report postoperative problems than those treated in NHS facilities (aOR: $0.35 ; 95 \% \mathrm{CI}[0.17,0.70]$ ), and improvements were greater in patients treated in private centres. The authors highlighted that private centres tend to treat less severe primary cataract cases.

Bannister et al. ${ }^{24}$ and Chard et al. ${ }^{5}$ examine safety issues between the private and public facilities after hip and knee surgeries. Bannister et al. ${ }^{24}$ reported on readmission, reoperation, dislocation rates, and wound problems, while Chard et al. ${ }^{5}$ presented complication rates as a safety criterion. Chard et al. ${ }^{5}$ found that patients undergoing joint replacements in public facilities reported complications more often and hypothesized that this could be due to patient selection. Bannister et al. ${ }^{24}$ compared short-term complications of THR and total knee replacement (TKR) at one NHS hospital with two ISTCs. Their study reported lower complication rates for surgeries performed in the NHS hospital, in contrast to Chard et al ${ }^{5}$.

Kelly and Stoye ${ }^{25}$ stated that after the introduction of private hospitals on the public market for elective hip replacements, the 30-day emergency readmission rate dropped from $6.1 \%$ (2002-03) to 5.6\% (2012-13) in public hospitals, but these changes were not statistically significant. In 2012-13, 30day emergency readmission rates following hip replacement were lower at private hospitals: $5.6 \%$ and $3.5 \%$ respectively. The authors concluded that readmission rates were unaffected by the reforms.

\section{Australia}

Li et al. ${ }^{19}$ studied the sociodemographic, environmental, and clinical risk factors for postoperative endophthalmitis, using administrative data from Western Australia. The results showed that procedures performed in private hospitals had a significantly higher risk of postoperative infection (OR 2.38; $95 \% \mathrm{Cl} 1.32-4.27 ; \mathrm{p} 0.003$ ) than those performed in public hospitals.

Naylor et al. ${ }^{11}$ conducted a telephone survey of Australian arthroplasty patients at eight public and seven private high-volume providers on the 35th postoperative day. Cohort analysis by arthroplasty type and sector showed that the rate of complications was different for hip arthroplasty (public $23 \%$ vs 
private $37 \%, p<0.01)$ but were the same for knee arthroplasty $(16 \%)$.

Denmark

Two studies ${ }^{13,14}$ were conducted in Denmark to compare elective surgeries in private versus public hospitals. The first study showed that overall mortality in patients who had cataract surgery in public hospitals was $62 \%$ (IRR: $1.62,95 \% \mathrm{Cl}$ : $1.59-1.66, \mathrm{p}<0.001$ ) higher than patients who had cataract surgery in private clinics between 2002 and $2010^{13}$. Patient selection could contribute to this difference, as patients treated in public facilities were more deprived than those in private clinics. The second study addressed the risk of cataract surgery complication (endophthalmitis) in private clinics versus public health care centres between 2004 and 2012 and showed that endophthalmitis risk is two times as high ( 0.73 per 1,000 procedures compared with 0.36 per 1,000 procedures) in private surgical centres ${ }^{14}$. This finding reinforces findings from earlier research by Li et al. ${ }^{19}$ and others.

A third Dutch study by Andersen and Jakobsen ${ }^{3}$ examined complication rates as a safety criterion after hip and knee surgeries. They found that patients undergoing joint replacements in public facilities reported complications more often. The reason could be patient selection as patients undergoing surgery in private centres were healthier and were less prone to complications relative to those undergoing surgery through public providers.

Italy

Like Kelly and Stoye ${ }^{25}$, Moscone et al. ${ }^{27}$ evaluated 30-day emergency readmission rates for publicly funded hip and knee replacement patients to investigate the difference between the public and private providers using an IV approach. Using 2012-14 administrative data on patients admitted to 189 hospitals in Italy, they found that the risk of readmission following hip replacement in private facilities was $3.6 \%$ higher than in public facilities ( $p=0.032$ ).

Norway

Holom and Hagen ${ }^{18}$ evaluated publicly financed primary total hip $(37,897)$ and total knee arthroplasty $(25,802)$ patients for six years in Norway. They concluded that private non-profit hospitals had significantly lower rates for 30 -day readmission due to complications $(0.049 \pm 0.217$ for private not-forprofit hospitals and $0.080 \pm 0.272$ for public hospitals), despite finding that quality differences between hospital types (private for-profit hospitals, private not-for-profit hospitals, and public hospitals) were minor. The authors suggest that this may be because public hospitals receive more readmissions and play a critical role in the care of more complex cases.

\subsubsection{Clinical effectiveness}

Clinical effectiveness can be assessed by many outcomes, such as improvements life-years gained, symptom relief, patient-reported outcomes, or cure. Researchers explored postoperative outcomes, readmission rates, reoperation rates, or short-term complications of surgical procedures as a clinical effectiveness factor in seven studies $2,5,7,12,23,24,28$.

The most extensive research on the correlation between clinical effectiveness and care provider types was conducted in the UK ${ }^{5,23,24}$ and Australia $2,7,12$. United Kingdom

Browne et al. ${ }^{23}$ evaluated 769 patients treated in six ISTCs, and 1,895 patients treated in 20 NHS facilities in England. They found that functional status and quality of life improvement were more significant for the patients who had cataract surgery or hip replacement in ISTCs than those had surgery in NHS facilities. After adjusting for preoperative characteristics, they found favourable and statistically significant differences persisted for patients treated at ISTCs. The study outcomes are reported as follows: Visual Function 14 (VF-14) scores were 2.6 points higher $(p=0.005)$ and the EQ-5D 0.03 points higher $(p=0.01)$ for cataract surgery patients at ISTCs, and for hip replacement patients, Oxford Hip Scores $(\mathrm{OHS})$ were 2.4 points higher $(p=0.03)$ and the EQ-5D scores were 0.06 points higher $(p=0.03)$ for ISTC patients.

Bannister et al. ${ }^{24}$ examined short-term complications after total hip and knee arthroplasties at an NHS hospital and two ISTCs. They found that after total hip arthroplasty, the NHS facility had a lower rate of complications requiring reoperation than ISTCs. After total knee arthroplasties, readmission rates at a private hospital (13\%) were 12 times higher than a regional orthopedic hospital and 13 times greater than NHS (1.1\% and 1\% respectively; chi-square test: $108 ; p=0.000$ ). After total hip arthroplasty, reoperation rates at the regional orthopedic hospital were at $0.6 \%$, NHS $1.4 \%$, and private hospital $9 \%$.

A study by Chard et al. ${ }^{5}$ provided information on clinical outcomes after hip and knee surgery. The authors evaluated the characteristics of patients undergoing hip and knee replacement (5,671 in ISTCs and 14,292 in NHS), inguinal hernia repair, or varicose vein surgery. The comparison of symptoms and health-related quality of life scores showed that hip and knee replacements performed by ISTC surgeons had better outcomes than the procedures undertaken by the physicians who work at the public hospitals (difference of 1.7 in OHS and 1.4 for Oxford knee score). The authors stated that these differences were minor, thus, unlikely to be clinically significant. Chard et al. ${ }^{5}$ suggested a possible reason for the better outcomes could be that these facilities admitted healthier patients or patients who had less severe conditions than those undergoing surgery in NHS providers.

Australia

Pager and McCluskey ${ }^{12}$ looked at 42 public and 39 private day-surgery cataract patients' priorities, satisfaction levels, and postoperative outcomes. Comparing preoperative and postoperative VF-14 (Visual Function Index) scores, results showed that both groups achieved the same level of postoperative 
outcomes. Preoperative VF-14 scores were 86.5 (Standard Deviation [SD] \pm 11.7 ) for private patients and 79.0 (SD \pm 19 ) for public patients, and after the procedure, the VF-14 scores reached $91.5(\mathrm{SD} \pm 13)$ and 92.8 (SD \pm 14$)$, for private and public patients, respectively.

Other studies from Australia ${ }^{2,7}$ evaluate the clinical effectiveness of hip and knee replacement. Adie et al. ${ }^{2}$ found similar outcomes (magnitude and rate of improvement in Oxford score or quality of life) for patients treated in public and private hospitals, while Harris et al. ${ }^{7}$ reported higher revision rates for THR (17.4\% private vs $4.4 \%$ public) and TKR (19.6\% private vs $10.0 \%$ public) in private hospitals. The authors highlighted that this variation was mainly due to differences in prosthesis selection.

Netherlands

Tulp et al. ${ }^{28}$ compared ISTCs with public hospitals on quality and price for five elective surgeries (cataract, THR, TKR, anterior cruciate ligament, and carpal tunnel surgery). They found that revision surgery after THR was performed more frequently in private facilities than in public hospitals. A regression analysis estimated a $1.44 \%$ higher revision rate in private facilities. These quality differences were not consistent over all elective surgery types and providers. ISTCs performed on worse for both TKR and THR, yet outperformed public hospitals for cataract treatment.

\subsubsection{Efficiency}

Efficiency refers to how to use resources effectively to achieve an objective ${ }^{32}$. Surgical service efficiency was examined in ten studies ${ }^{4,10,15,16,19-22,25,28 .}$ Most of the research adopted the technical efficiency perspective, so the authors evaluated length of stay (LOS), defined as from admission to discharge or preoperative only $4,16,18,20,21,25$, and a number of the surgical procedures completed in a year ${ }^{15,19,25}$.

United Kingdom

Studies from the UK on efficiency report varied results. Two studies ${ }^{20,21}$ evaluated the effect of private sector exposure on preoperative LOS in public facilities. Kelly and Stoye ${ }^{21}$ evaluated geographic areas where the independent sector providers were closer to patients than the NHS hospitals, yet did not find any effect of independent sector provider exposure on preoperative LOS; however, the researchers reported that NHS funded hip replacement numbers increased annually by 0.5 procedures per Middle Layer Super Output Area (MSOA). The authors explained this increase by hypothesizing that independent sector providers operated on patients who would not otherwise have undergone a hip replacement.

Using a large dataset which covers 615,281 patients who had hip replacement surgery both in private and public facilities between April 2002 and March 2013, Kelly and Stoye ${ }^{25}$ found a five day decrease in median LOS (from 9 to 4 days) at public hospitals over the study period. In 2012-13, the median LOS is the same for public and private providers. Study results also showed that private hospitals' entry into the publicly funded elective surgery market increased the total number of publicly funded hip replacements provided, without reducing the total number of cases in the public facilities.

Contrasting these results, Cooper et al. ${ }^{20}$ found that hospitals located in more competitive markets were more successful in decreasing LOS. They found the entry of for-profit specialty surgical centres led to a $16 \%$ reduction in pre-surgery LOS at nearby public hospitals, increasing the proportion of patients treated on the day of admission.

Vanhegan et al. ${ }^{15}$ evaluated the effect of an ISTC on the provision of elective orthopedic surgery in England and found that the same surgeon operated on 66 patients in a public facility prior to the introduction of ISTCs, and just 32 patients in the ISTC after the introduction of the ISTC, a reduction in productivity of $51 \%$. They found the introduction of the ISTC resulted in a reduction in departmental efficiency and financial productivity. The researchers reported a combined reduction in potential financial productivity of $£ 128,677$ over three months or $£ 514,708$ over a year, based on 2011 tariffs ${ }^{15}$.

Another UK study, by Street et al. ${ }^{22}$, compared outcomes between hospitals and private treatment centres by applying six indicators to assess healthcare resource group (HRGs) intensity: age, LOS, number of diagnoses, number of procedures, income deprivation and transferred to other NHS providers. The study results showed very little difference in LOS (weighted mean difference -0.25 days, $99 \% \mathrm{Cl}-0.28$ to -0.22 ) between patients treated in hospitals and treatment centres except for hip and knee replacements. Those receiving hip and knee replacement surgeries in public facilities had stayed longer than those treated in private treatment centres.

Siciliani et al. ${ }^{16}$ evaluated whether provision of care in specialized treatment centres is more efficient than in hospital settings. They investigated differences in LOS for hip replacement patients and found the specialized public treatment centres (5.866 \pm 2.572$)$ and private treatment centres (4.481 \pm 1.494$)$ have $18 \%$ and $40 \%$ shorter LOS than public hospitals $(7.455 \pm 4.780)$, respectively.

Austria

Barbieri et al. ${ }^{4}$ compared the LOS and found that private hospitals had a significantly shorter average LOS than public hospitals ( 2.97 compared with 4.21 days). The authors explained the difference by stating that public hospitals often performed additional procedures during one admission.

Australia

Using population-based administrative data from Western Australia, Li et al. ${ }^{19}$ compared public and private facilities and found that more cataract surgeries were performed in private hospitals than in public hospitals and hospitals in rural areas.

Netherlands 
Tulp et al. ${ }^{28}$ compared ISTCs with general hospitals and provide efficiency information on five elective surgeries (cataract, total hip and knee replacement, anterior cruciate ligament, and carpal tunnel surgery). All procedures except anterior cruciate ligament surgery were performed more often in the public hospital setting, leading to lower list prices for procedures, although the effect is limited.

Canada

Koehoorn et al. ${ }^{10}$ evaluated the effect of expedited surgical fees paid to physicians in reducing wait time and return to work time in public and private facilities in British Columbia, Canada. Aiming to reduce surgery wait times, disability costs and improve return-to-work outcomes, some workers' compensation systems in Canada pay (higher) fees to expedited surgeries. Policies vary among provinces, but in this approach, clinics are expected to perform expedited operations within 21 days of surgery decision. Study results revealed that the public expedited group had the shortest disability duration from surgical consult to return to work around one workweek.

\subsubsection{Cost and cost-effectiveness}

Goodacre and McCabe define a cost-effective intervention as an intervention that represents good value for money ${ }^{33}$. A broader definition of costeffectiveness is: "The achievement of results in the most economical way. This approach assesses efficiency by checking whether resources are being used to produce any given results at the lowest possible cost. Cost-effectiveness is most relevant as a concept of efficiency in cases such as the provision of defence, education, health care, policing, or environmental protection, where it is sometimes difficult to measure the monetary value of the results achieved." 34

Australia

Karnon et al. ${ }^{8}$ assessed the cost-effectiveness of contracting with the private sector for TKR. Using secondary data, the authors developed a decision tree and a Markov model. The study population comprised of patients categorized as non-urgent. The authors used the Western Ontario and McMaster Universities Arthritis Index to represent patients' health status. The analysis was undertaken from the Australian health system perspective, and the authors found that with the purchase of private services, additional quality-adjusted life years (QALYs) could be gained at an incremental cost of less than 40,000 2016 Australian Dollars. They concluded that alternative options for increased government funding of TKR might be more cost-effective than many new publicly funded pharmaceuticals in Australia. To our knowledge, this is the only study that demonstrates the cost-effectiveness of contracting with the private sector for TKR.

Netherlands

Kruse et al. ${ }^{26}$ compared the claim costs for cataract surgery between ISTCs and public facilities. They found that ISTCs costs were 7\% lower compared to public facilities for both 2013 and 2014. The authors explained that with the fewer care activities claimed by ISTCs, lower costs in ISTCs were due to more intense optometrist use and lower overhead costs.

\subsubsection{Patient characteristics and selection issues}

Our review also identified additional important findings around the selection of patients receiving care in different facility types. Terms such as cherrypicking, cream-skimming, and dumping were used in several studies to describe approaches to patient selection by private providers $4,5,12-14,18,20,22-24$.

Generally, private facilities are alleged to cherry-pick or cream-skim by selecting less complex patients, which (i) increases postoperative LOS and costs for public facilities, (ii) restricts access to private facilities for certain groups of patients, and (iii) increases inequality within the health system ${ }^{5,13,23}$. Dumping occurs when patients from private facilities are referred to public facilities in the event of adverse surgical outcomes ${ }^{14}$.

Thirteen papers compared the characteristics of patients undergoing cataract, orthopedic surgery at private surgical clinics with public facilities. They found that patients who have surgery in private hospitals are healthier $5,13,23$ and younger ${ }^{13,18,22}$ than those who have surgery in public hospitals. Private hospital patients also have fewer comorbidities ${ }^{18,23}$ and less severe preoperative symptoms $5,12,20,23$.

Cherry Picking

In the 2000s, after the implementation of for-profit and not-for-profit healthcare providers in the UK, public sector providers faced a staff shortage. At the same time, private centres took on less problematic patients and left the others to the public health care providers ${ }^{20}$. As a result, the public sector had to deal with more complex cases, comorbidities, and complications with fewer staff.

Case selection was also evaluated by Bannister et al. ${ }^{24}$. In contrast to previous studies ${ }^{18,23}$, they found that one ISTC rejected $1 \%$ of referred surgical cases due to the complexity of the surgery and $4.2 \%$ due to associated co-morbidities. Discussions around the potential for shifting such patients to the public system raise another concern regarding private sector provision.

Street et al. ${ }^{22}$ analyzed the UK hospital episode statistics and compared the characteristics of patients treated in ISTCs and hospitals in 2006. Of $3,334,535$ patients, $2.3 \%$ were treated in private centres. They found that patients treated in public centres were younger, more likely to have come from deprived areas, and tended to have more diagnostic and procedure codes than those treated in private centres. 
Barbieri et al. ${ }^{4}$ detected differences in the hospitalization of cataract patients in Austria. They found that the rates for cataract intervention in both eyes were nearly three times higher in public hospitals ( $7.01 \%$ public compared with $2.47 \%$ private).

A UK study ${ }^{5}$ compared characteristics of ISTC and public health care centre patients. A three- to six-month follow-up on outcomes after elective surgery showed that patients treated by ISTCs were healthier and admitted with less severe symptoms than the patients treated by the public health care providers, though the difference was small. The results of this study do not appear to support cherry-picking concerns.

Similarly, another UK study ${ }^{25}$ showed that the mean age and the mean number of comorbidities are slightly lower for the patients treated at private hospitals in 2012-13 compared to the public hospitals. The mean number of comorbidities was 1.8 for patients treated in private facilities and 3.1 for the ones treated in NHS hospitals.

Kruse et al. ${ }^{26}$ found that ISTCs generally perform less severe patients' cataract surgeries. They attribute this finding to Dutch treatment guidelines which ISTCs must follow, requiring them to refrain from treating patients with severe systematic diseases according to American Society of Anesthesiologists Classification System (ASA type III).

Moscone et al. ${ }^{27}$ also found that severe patients who require hip and knee surgery were less likely to be admitted to private facilities, consistent with some other studies ${ }^{26}$. They suggest this is due to either a lack of facilities to treat the patients with a high comorbidity index or specialization in routine cases, or a combination of dumping and cherry-picking.

Dumping

A study from Denmark revealed a strong indicator of dumping, as the researchers found that all endophthalmitis cases after cataract surgery (36\% performed at public hospitals and 64\% performed at private hospitals) were treated in public hospitals between 2002 and $2010{ }^{14}$.

\section{Discussion}

In this review, we evaluated the three main dimensions of healthcare quality alongside efficiency and cost considerations: safety, clinical effectiveness, and patient experience (accessibility and acceptability) ${ }^{35}$.

The results of the primary studies provide a mixed picture of the outcomes for private and public provision. Some results suggest that private sector provision has a positive impact on public health system providers' outcomes primarily due to competition ${ }^{20}$, and higher degrees of competition are associated with greater improvements in quality ${ }^{36}$. Studies also show increased quality of care in hospitals located in more competitive areas than hospitals located in less competitive areas, without increased expenditures ${ }^{36,37}$. Although the evidence suggests that competition increases health system quality ${ }^{38}$, price regulation mechanisms are also important. Private surgical clinics generally refuse to disclose their financial statements, making it difficult to know the extent to which inappropriate or unnecessary surgeries occur in the private sector. Theoretical models show that when delivery side competition is combined with price regulation, wait times are reduced, and patient's quality of care increases ${ }^{39}$. Although the included studies used various methods, only four $18,21,25,27$ applied causal inference methods rather than regression-based approaches with controls.

There is limited evidence that private sector contracts within the publicly funded health system will address existing problems of capacity and waiting times in healthcare delivery. Even though there were statistically significant reductions in wait times for patients treated in private facilities in most studies, the evidence on the importance of wait times on patient preferences is controversial. A recent Australian study ${ }^{40}$ identified the five most important attributes that patients consider when making decisions about cataract surgery in an urban setting are surgical wait time, cost, travel time, hospital reputation, and surgeon experience. This qualitative study has two main limitations. First, it does not reflect the preferences of individuals seeking cataract surgery in rural areas of Australia. They may prioritize distance over surgical wait time. Secondly, non-English speaking participants' results are different than those English-speaking participants. Non-English-speaking participants indicated that they were content to wait for surgery on the condition that they did not have to pay ${ }^{40}$. As described above, the evidence so far remains mixed. Private sector providers are expected to be more efficient due to their ability to treat patients more quickly, but some available evidence challenges this view ${ }^{41-43}$. Even if private sector providers treat more patients in a given time period, implications for the relative quality, cost-effectiveness, and efficiency of such services are unclear. Opponents of private sector provision remain concerned that private centres would engage in patient selection strategies, cherry-picking, cream-skimming, and dumping ${ }^{20}$.

Tynkkynen and Vrangbaek ${ }^{44}$ conducted a scoping review on public and private provision in Europe, and included four of the same studies as this review ${ }^{3}$ $13,14,17$ as well as an overview of other systematic reviews ${ }^{45}$. Their findings are partially consistent with ours. The authors found that although public hospitals treat patients with more comorbidities and complications who are older and more socioeconomically deprived, they consistently have better economic performance than the private ones. The review concluded that several studies addressing the economic effects of the private compared with the public provision of health care fail to consider quality and other operational dimensions, a critical blind spot that may influence results.

In an overview of systematic reviews, Herrera et al. ${ }^{45}$ reviewed 5,918 studies to identify systematic reviews on the impact of different types of ownership on economic, administrative, and health-related outcomes. The authors analyzed nine systematic reviews and found that for-profit healthcare providers seem to have worse mortality outcomes than their not-for-profit and public counterparts. They concluded that substantial evidence gaps in the literature remain in the comparison between public and private sector providers.

Page 9/14 


\section{Conclusions}

The evidence from the reviewed studies is mixed. Some studies found that public hospitals are more efficient than private ones, while others found no significant difference. Few studies explicitly sought to examine the accessibility, acceptability, safety, and cost-effectiveness of the private sector provision of surgical services within publicly operated health systems.

Wait times were shorter for patients treated in private facilities in most studies, while inequalities by age and socioeconomic deprivation were found to increase with a private provision in some studies. Acceptability results were mixed, with most studies finding no differences between public and private provision and others finding higher satisfaction at public facilities. Results for safety outcomes were divided, but most studies finding improved safety outcomes in private facilities noted private patients had a lower preoperative risk of complications. Clinical effectiveness was similar in most studies, with differences in outcomes mainly attributed to patient selection or prosthesis choice. Very few studies reported cost and cost-effectiveness outcomes, and two studies conclude that private facilities are economically viable within publicly funded health systems.

There are still important evidence gaps to assess the quality of these services. Value for money also remains to be evaluated properly. Additionally, nonmonetary concerns (for example, potential outcomes) are also being ignored, leading to biased evaluations.

\section{Abbreviations}

aOR

adjusted odds ratio

ASA

American Society of Anesthesiologists Classification System

ISTCs

Independent Sector Treatment Centres

IV

Instrumental variable

LOS

Length of stay

NHS

National Health Service

$\mathrm{OHS}$

Oxford Hip Scores

OLS

Ordinary least square

OR

odds ratio

PRISMA

Preferred Reporting Items for Systematic Reviews and Meta-Analyses

QALYS

Quality Adjusted Life Years

SD

Standard Deviation

THR

Total hip replacement

TKR

Total knee replacement

VF-14

Visual Function Index

\section{Declarations}

Ethics approval and consent to participate: Not applicable

Consent for publication: Not applicable

Availability of data and materials: All data generated or analyzed during this study are included in this published article [and its supplementary information files].

Competing interests: The authors declare that they have no competing interests

Funding: The author(s) received no financial support for the research, authorship, and/or publication of this article. 
Authors' contributions: IA: Conceptualization, Methodology, Formal analysis, Writing - Original Draft, Writing - Review \& Editing, Visualization, EK: Methodology, Formal analysis, Writing - Original Draft, Writing - Review \& Editing, Visualization, LT: Methodology, DC: Methodology, JR: Conceptualization, Methodology, Writing - Review \& Editing. All authors read and approved the final manuscript.

Acknowledgements: Not applicable

\section{References}

1. Bachelet VC, Goyenechea M, Carrasco VA. Policy strategies to reduce waiting times for elective surgery: A scoping review and evidence synthesis. Int J Health Plann Manage 2019.

2. Adie S, Dao A, Harris IA, Naylor JM, Mittal R. Satisfaction with joint replacement in public versus private hospitals: A cohort study. ANZ Journal of Surgery 2012;82(9):616-24.

3. Andersen LB, Jakobsen ML. Does ownership matter for the provision of professionalized services? Hip operations at publicly and privately owned clinics in denmark. Public Administration 2011;89(3):956-74.

4. Barbieri V, Schmid E, Ulmer H, Pfeiffer KP. Health care supply for cataract in austrian public and private hospitals. European Journal of Ophthalmology 2007;17(4):557-64.

5. Chard J, Kuczawski M, Black N, van der Meulen J, Committee OAS. Outcomes of elective surgery undertaken in independent sector treatment centres and nhs providers in England: Audit of patient outcomes in surgery. BMJ 2011;343:d6404

6. Fitzpatrick R, Norquist JM, Reeves BC, Morris RW, Murray DW, Gregg PJ. Equity and need when waiting for total hip replacement surgery. Journal of Evaluation in Clinical Practice 2004;10(1):3-9.

7. Harris I, Cuthbert A, Lorimer M, de Steiger R, Lewis P, Graves SE. Outcomes of hip and knee replacement surgery in private and public hospitals in Australia. ANZ Journal of Surgery 2019;08:08.

8. Karnon J, Haghighi B, Sajjad B, Yem S, Gamage A, Thorpe A. Cost-utility analysis of private contracting to reduce public waiting times for joint replacement surgery. International Journal of Technology Assessment in Health Care 2018;34(2):147-55.

9. Kirkwood G, Pollock AM. Patient choice and private provision decreased public provision and increased inequalities in Scotland: A case study of elective hip arthroplasty. Journal of Public Health 2017;39(3):593-600.

10. Koehoorn M, McLeod C, Fan J, McGrail K, Barer M, Cote P, et al. Do private clinics or expedited fees reduce disability duration for injured workers following knee surgery? Healthcare Policy = Politiques de sante 2011;7(1):55-70.

11. Naylor JM, Descallar J, Grootemaat M, Badge H, Harris I, Simpson G, et al. Is satisfaction with the acute-care experience higher amongst consumers treated in the private sector? A survey of public and private sector arthroplasty recipients. PLoS ONE [Electronic Resource]2016;11(8):e0159799.

12. Pager C, McCluskey P. Public versus private patient priorities and satisfaction in cataract surgery. Clinical \& Experimental Ophthalmology 2004;32(5):482-7.

13. Solborg Bjerrum S, Mikkelsen K, la Cour M. Epidemiology of 411140 cataract operations performed in public hospitals and private hospitals/clinics in denmark between 2004 and 2012. Acta Opthalmologica 2015;93(1):16-23.

14. Solborg Bjerrum S, Kiilgaard J, Mikkelsen K, la Cour M. Outsourced cataract surgery and postoperative endophthalmitis. Acta Opthalmologica 2013;91(8):701-8

15. Vanhegan I, Hakmi A, de Roeck N, Rumian A. Effect of an independent-sector treatment centre on provision of elective orthopaedic surgery in east and north hertfordshire. Annals of the Royal College of Surgeons of England 2015;97(7):519-25.

16. Siciliani L, Sivey P, Street A. Differences in length of stay for hip replacement between public hospitals, specialised treatment centres and private providers: Selection or efficiency? Health Economics 2013;22(2):234-42.

17. Perotin V, Zamora B, Reeves R, Bartlett W, Allen P. Does hospital ownership affect patient experience? An investigation into public-private sector differences in England. Journal of Health Economics 2013;32(3):633-46.

18. Holom G, Hagen T. Quality differences between private for-profit, private non-profit and public hospitals in norway: A retrospective national registerbased study of acute readmission rates following total hip and knee arthroplasties. BMJ Open 2017;7 (8) (no pagination)(e015771).

19. Li J, Morlet N, Ng J, Semmens J, Knuiman M. Significant nonsurgical risk factors for endophthalmitis after cataract survey: Epswa fourth report. Investigative Ophthalmology and Visual Science 2004;45(5):1321-8.

20. Cooper Z, Gibbons S, Skellern M. Does competition from private surgical centres improve public hospitals' performance? Evidence from the English national health service. Journal of Public Economics 2018;166:63-80.

21. Kelly E, Stoye G. New joints: Private providers and rising demand in the English national health service. Institute for Fiscal Studies, IFS Working Papers: W16/15; 2016. https://www.ifs.org.uk/uploads/publications/wps/WP201615.pdf.Accessed 18 May 2020.

22. Street A, Sivey P, Mason A, Miraldo M, Siciliani L. Are English treatment centres treating less complex patients? Health Policy 2010;94(2):150-7.

23. Browne J, Jamieson L, Lewsey J, van der Meulen J, Copley L, Black N. Case-mix \& patients' reports of outcome in independent sector treatment centres: Comparison with nhs providers. BMC Health Serv Res 2008;8:78.

24. Bannister G, Ahmed M, Bannister M, Bray R, Dillon P, Eastaugh-Waring S. Early complications of total hip and knee replacement: A comparison of outcomes in a regional orthopaedic hospital and two independent treatment centres. Ann R Coll Surg Eng/2010;92(7):610-4. 
25. Kelly E, Stoye G. The impacts of private hospital entry on the public market for elective care in England. Journal of Health Economics 2020;73.

26. Kruse F, Groenewoud S, Atsma F, van der Galien O, Adang E, Jeurissen PP. Do independent treatment centers offer more value than general hospitals? The case of cataract care. Health Serv Res 2019;54(6):1357-65.

27. Moscone F, Siciliani L, Tosetti E, Vittadini G. Do public and private hospitals differ in quality? Evidence from italy. Regional Science and Urban Economics 2020;83.

28. Tulp A, Kruse F, Stadhouders N, Jeurissen P. Independent treatment centres are not a guarantee for high quality and low healthcare prices in the Netherlands - a study of 5 elective surgeries. Int 2020;9(9):380-9.

29. Gulliford M, Figueroa-Munoz J, Morgan M, Hughes D, Gibson B, Beech R, et al. What does' access to health care' mean? Journal of Health Services Research\& Policy, 7(3), pp186-1882002.

30. Sekhon M, Cartwright M, Francis J. Acceptability of healthcare interventions: An overview of reviews and development of a theoretical framework. BMC Health Serv Res 2017;17(1):88.

31. Hundt A, Carayon P, Springman S, Smith M, Florek K, Sheth R, et al. Outpatient surgery and patient safety- the patient's voice. In: Henriksen K, Battles JB, Marks ES, Lewin DI, editors. Advances in patient safety: From research to implementation (volume 4: Programs, tools, and products). Advances in patient safety. Rockville (MD)2005.

32. CIHI. Health system efficiency in Canada: Why does efficiency vary among regions? April 2014.

https://www.cihi.ca/en/hse_short_aib_10apr14_en.pdf.Accessed 20 May 2020

33. Goodacre S, McCabe C. An introduction to economic evaluation. Emerg Med J 2002;19(3):198-201.

34. Black J, Hashimzade N, Myles GD. A dictionary of economics. 4th ed: Oxford University Press; 2012. http://www.oxfordreference.com/view/10.1093/acref/9780199696321.001.0001/acref-9780199696321.Accessed 20 May 2020.

35. Doyle C, Lennox L, Bell D. A systematic review of evidence on the links between patient experience and clinical safety and effectiveness. $B M J$ Open;2013;3(1):e001570.

36. Cooper Z, Gibbons S, Jones S, McGuire A. Does hospital competition save lives? Evidence from the English nhs patient choice reforms. Econ J (London) 2011;121(554):F228-F60.

37. Gaynor M, Moreno-Serra R, Propper C. Death by market power: Reform, competition and patient outcomes in the national health service. CEPR Discussion Papers 2011.

38. Gaynor M, Moreno-Serra R, Propper C. Can competition improve outcomes in UK health care? Lessons from the past two decades. Journal of Health Services Research \& Policy 2012;17(S1).

39. Propper C. Competition in health care: Lessons from the English experience. Health Econ Policy Law 2018;13(3-4):492-508.

40. Gilbert C, Keay L, Palagyi A, Do V, McCluskey P, White A, et al. Investigation of attributes which guide choice in cataract surgery services in urban sydney, Australia. Clin Exp Optom 2018;101(3):363-71.

41. Kruse F, Stadhouders N, Adang E, Groenewoud S, Jeurissen P. Do private hospitals outperform public hospitals regarding efficiency, accessibility, and quality of care in the European union? A literature review. International Journal of Health Planning and Management 2018;33(2):434.

42. Modi N, Clarke J, McKee M. Health systems should be publicly funded and publicly provided. BMJ (Clinical Research Ed) $2018 ; 362$.

43. Vengberg S, Fredriksson M, Winblad U. Patient choice and provider competition - quality enhancing drivers in primary care? Soc Sci Med 2019;226:217-24.

44. Tynkkynen LK, Vrangbaek K. Comparing public and private providers: A scoping review of hospital services in Europe. BMC Health Serv Res 2018;18(1):141.

45. Herrera C, Rada G, Kuhn-Barrientos L, Barrios X. Does ownership matter? An overview of systematic reviews of the performance of private for-profit, private not-for-profit and public healthcare providers. PLOS ONE [Electronic Resource] 2014;9(12):1-18.

\section{Tables}

Table 1: Data extracted during the review 


\begin{tabular}{|c|c|c|c|c|c|c|c|c|c|}
\hline Study & Country & Case & Accessibility & Acceptability & Safety & $\begin{array}{l}\text { Clinical } \\
\text { effectiveness }\end{array}$ & Efficiency & $\begin{array}{l}\text { Cost/cost- } \\
\text { effectiveness }\end{array}$ & Others \\
\hline Adie et al. $2012^{2}$ & Australia & $\begin{array}{l}\text { Hip and } \\
\text { knee }\end{array}$ & & + & & + & & & \\
\hline $\begin{array}{l}\text { Andersen and } \\
\text { Jakobsen } 2011^{3}\end{array}$ & Denmark & Hip & + & + & + & & & & \\
\hline $\begin{array}{l}\text { Bannister et al. } \\
2010^{24}\end{array}$ & UK & $\begin{array}{l}\text { Hip and } \\
\text { knee }\end{array}$ & & & + & + & & & + \\
\hline $\begin{array}{l}\text { Barbieri et al. } \\
2007^{4}\end{array}$ & Austria & Cataract & & & & & + & & + \\
\hline $\begin{array}{l}\text { Browne et al. } \\
2008^{23}\end{array}$ & UK & $\begin{array}{l}\text { Cataract, } \\
\text { inguinal } \\
\text { hernia, } \\
\text { varicose } \\
\text { vein }\end{array}$ & & + & + & + & & & + \\
\hline Chard et al. $2011^{5}$ & UK & $\begin{array}{l}\text { Hip and } \\
\text { knee, } \\
\text { inguinal } \\
\text { hernia, } \\
\text { varicose } \\
\text { veins }\end{array}$ & & & + & + & & & + \\
\hline $\begin{array}{l}\text { Cooper et al. } \\
2018^{20}\end{array}$ & UK & $\begin{array}{l}\text { Hip and } \\
\text { knee }\end{array}$ & & & & & + & & + \\
\hline $\begin{array}{l}\text { Fitzpatrick et al. } \\
2004^{6}\end{array}$ & UK & Hip & + & & & & & & \\
\hline Harris et al. $2019^{7}$ & Australia & $\begin{array}{l}\text { Hip and } \\
\text { knee }\end{array}$ & & & & + & & & \\
\hline $\begin{array}{l}\text { Holom and } \\
\text { Hagen } 201718\end{array}$ & Norway & $\begin{array}{l}\text { Hip and } \\
\text { knee }\end{array}$ & & & + & & & & + \\
\hline $\begin{array}{l}\text { Karnon et al. } \\
2018^{8}\end{array}$ & Australia & Knee & & & & & & + & \\
\hline $\begin{array}{l}\text { Kelly and } \\
\text { Stoye } 2016^{21}\end{array}$ & UK & Hip & + & & & & + & & \\
\hline $\begin{array}{l}\text { Kelly and } \\
\text { Stoye } 2020^{25}\end{array}$ & UK & Hip & + & & + & & + & & + \\
\hline $\begin{array}{l}\text { Kirkwood and } \\
\text { Pollock } 2017^{9}\end{array}$ & UK & Hip & + & & & & & & \\
\hline $\begin{array}{l}\text { Koehoorn et al. } \\
2011^{10}\end{array}$ & Canada & Knee & + & & & & + & & \\
\hline Kruse et al. 201926 & Netherlands & Cataract & + & + & & & & + & + \\
\hline Li et al. $2004^{19}$ & Australia & Cataract & & & + & & + & & \\
\hline $\begin{array}{l}\text { Moscone et al. } \\
2019^{27}\end{array}$ & Italy & $\begin{array}{l}\text { Hip and } \\
\text { knee }\end{array}$ & + & & + & & & & + \\
\hline $\begin{array}{l}\text { Naylor et al. } \\
2016^{11}\end{array}$ & Australia & $\begin{array}{l}\text { Hip and } \\
\text { knee }\end{array}$ & & + & + & & & & \\
\hline $\begin{array}{l}\text { Pager and } \\
\text { McCluskey } 2004^{12}\end{array}$ & Australia & Cataract & + & + & & + & & & + \\
\hline $\begin{array}{l}\text { Perotin et al. } \\
2013^{17}\end{array}$ & UK & $\begin{array}{l}9 \\
\text { specialties }\end{array}$ & & + & & & & & \\
\hline $\begin{array}{l}\text { Siciliani et al. } \\
2013^{16}\end{array}$ & UK & Hip & & & & & + & & \\
\hline $\begin{array}{l}\text { Solborg et al. } \\
2015^{13}\end{array}$ & Denmark & Cataract & + & & + & & & & + \\
\hline $\begin{array}{l}\text { Solborg et al. } \\
2013^{14}\end{array}$ & Denmark & Cataract & & & + & & & & + \\
\hline
\end{tabular}




\begin{tabular}{|c|c|c|c|c|c|c|}
\hline Street et al. $2010^{22}$ & UK & $\begin{array}{l}\text { Cataract, } \\
\text { hip and } \\
\text { knee }\end{array}$ & & & + & + \\
\hline Tulp et al. 202028 & Netherlands & $\begin{array}{l}\text { Cataract, } \\
\text { hip and } \\
\text { knee, } \\
\text { anterior } \\
\text { cruciate } \\
\text { ligament, } \\
\text { carpal } \\
\text { tunnel } \\
\text { surgery }\end{array}$ & + & + & + & \\
\hline $\begin{array}{l}\text { Vanhegan et al. } \\
2015^{15}\end{array}$ & UK & $\begin{array}{l}\text { Upper } \\
\text { limb, foot } \\
\text { and ankle }\end{array}$ & & & + & \\
\hline
\end{tabular}

\section{Figures}

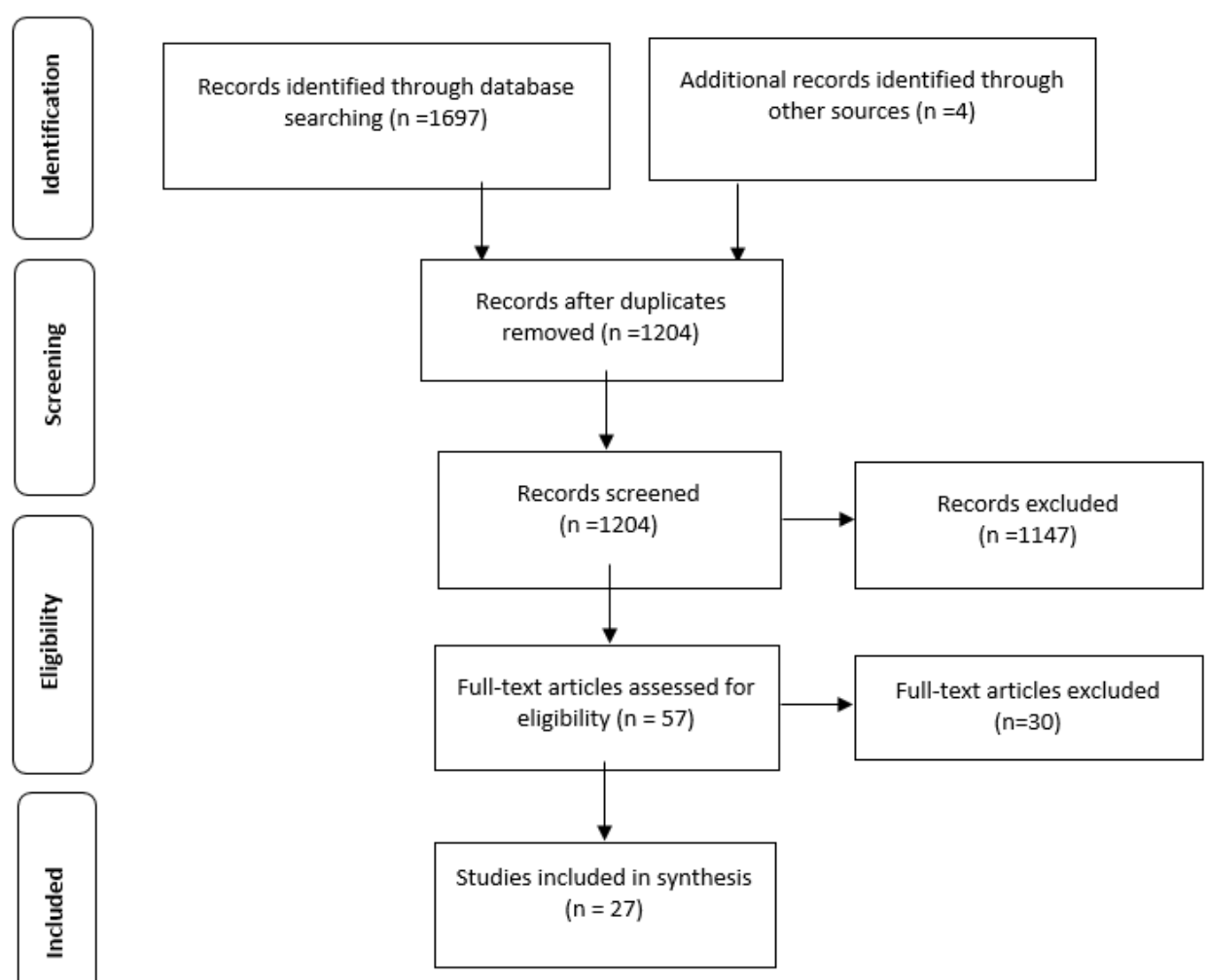

Figure 1

PRISMA Flow Diagram of Study Selection

\section{Supplementary Files}

This is a list of supplementary files associated with this preprint. Click to download.

- Additionalfile1.docx

- Additionalfile2.docx 